\title{
Factores relacionados con la dinámica del dengue en Guayaquil, basado en tendencias históricas
}

\section{Factors related to the dynamics of dengue in Guayaquil based on historical trends}

\author{
*Jhony Joe Real-Cotto 1,2,a \\ ${ }^{1}$ Dirección de Vigilancia de la Salud Pública CZ8-Salud/MSP, Ecuador. \\ ${ }^{2}$ Docente de la Universidad de Guayaquil, Ecuador. \\ ${ }^{a}$ MSc Epidemiología, MD
}

\section{Correspondencia \\ Jhony Real Cotto jreal_cotto@hotmail.com; realcottoj@gmail.com Ciudadela Polaris, Mz. 797, villa 12. Parroquia Tarqui, Guayaquil - Ecuador \\ Recibido, 14 abril 2016 \\ Evaluado, 26 mayo 2016 \\ Aceptado, 7 julio 2016 \\ Ningún conflicto de interes. El contenido del manuscrito no ha sido publicado previamente. Consentimiento informado: Aprobado por la Autoridad de la Zona 8 del Ministerio de Salud Pública del Ecuador. \\ Autofinanciado.}

Citar como: Real-Cotto JJ. Factores relacionados con la dinámica del dengue en Guayaquil, basado en tendencias climáticas históricas. An Fac med. 2017;78(1):23-8. DOI: http://dx.doi.org/10.15381/anales. v78i1.13017
An Fac med. 2017;78(1):23-8 / http://dx.doi.org/10.15381/anales.v7811.13017

Resumen

Introducción. La población de Guayaquil tiene presencia endémico - epidémica del dengue y existen pocos estudios sobre la tendencia histórica de los factores que influyen en el comportamiento. Objetivo. Establecer la tendencia histórica de los factores relacionados en la dinámica del dengue en la ciudad de Guayaquil, durante el período 2008 a 2013. Diseño. Estudio no experimental, tipo longitudinal de tendencia. Lugar. Ciudad de Guayaquil, Ecuador. Material. Casos de dengue. Método. Se obtuvo información de los casos de dengue, temperatura, humedad y vientos, indice de Breteau y virus circulantes. Principales medidas de resultados. Tendencia histórica de los factores relacionados en la dinámica del dengue. Resultados. La tendencia de más casos fue en las semanas 10 a 24 en los años 2010 y 2012, con dispersión de puntos comparado con la línea de tendencia. Las variables ambientales mostraron hallazgos de humedad por encima del $70 \%$ con temperatura altas y escasos vientos pueden provocar condiciones de incrementar la transmisión de la enfermedad. Existen periodos epidemiológicos donde su transmisión disminuye y puede estar relacionado a las temperaturas bajas, humedad relativa y presencia de vientos. Hubo presencia de los 4 serotipos de dengue, con circulación simultánea de los serotipos DEN1, DEN2, y DEN4 durante los últimos 3 años. Conclusiones. La tendencia histórica del dengue evidencia la presencia de la enfermedad durante todo el año, teniendo períodos y años de variabilidad en su incidencia. Los factores de temperatura, humedad, vientos e índice de Breteau presentaron más casos en los 2 primeros períodos de cada año. La tendencia polinómica fue del 63,3\%, considerándose fiable sobre el incremento de casos en la proyección al 2017.

Palabras clave. Dengue; Tendencia; Ambiente; Relación; Comportamiento.

\section{Abstract}

Introduction: Guayaquil population has an endemic - epidemic presence of dengue and there are few studies on the historical trend of the factors that influence its behavior. Objective: To establish the historical trend of factors relate to the dynamics of dengue in the city of Guayaquil during the period 2008 - 2013. Design. Non-experimental study, longitudinal trend. Setting: City of Guayaquil, Ecuador. Material: Cases of dengue. Methods: Information on cases of Dengue, temperature, humidity and wind, Breteau index and circulating viruses were obtained. Main outcome measures: Historical trend of the factors that influence the dynamics of dengue. Results: The trend with the most cases occurred in weeks 10-24 in 2010 and 2012, with scattering points compared to the trend line. Environmental variables showed findings of moisture above $70 \%$ with high and low winds that can cause conditions that may increase the transmission of the disease. The study also showed that there are epidemiological periods when the transmission decreases that may be related to lower temperatures, relative humidity and presence of wind. The 4 serotypes of dengue were present, with simultaneous movement of DEN1, DEN2 serotypes, and DEN4 serotypes for the past 3 years. Conclusions: The historical trend of dengue throughout the year has periods and years of variability. Environmental factors like temperature, humidity, winds and Breteau index accounted for more cases in the first 2 periods of each year. The polynomial trend was $63.3 \%$ which can be considered reliable on the increase in cases for the projection for 2017. It is important to continue the studies of the historical behavior of dengue with an integrated approach.

Keywords: Dengue; Environment; Relationship; Behavior. 


\section{INTRODUCCIÓN}

El Ecuador es calificado como uno de los países que tiene concentrada la mayor biodiversidad del planeta y que goza con una gran variedad de condiciones ecológicas por la influencia de la cordillera de los Andes, las corrientes marinas fría de Humboldt y la cálida del Niño. Estas dan origen a una gran diversidad de microclimas en cada región del país; así mismo, al influjo atmosférico, el rico sistema hidrográfico, las variaciones en la temperatura y los regímenes de precipitación, considerándose un país tropical donde se manifiestan en una amplia variedad de hábitats y ecosistemas, con presencia de vectores como el Aedes aegypti, transmisor de la enfermedad del dengue ${ }^{(1-4)}$.

Guayaquil es una ciudad a 5 m.s.n.m., donde hay una población concentrada en el área urbana y urbano-marginal, que representa el 22,5\% del país, con sectores deficientes de servicios básicos y una población periurbana con altas tasas de migración. Esta ciudad tiene antecedente de la mayor presencia de casos de dengue ${ }^{(5-6)}$, donde ha habido la circulación de los 4 virus dengue, alcanzando su mayor incidencia en la época invernal con condiciones ambientales favorables para su transmisión ${ }^{(7-8)}$; pero, se desconocía la influencia que tienen el ambiente, los virus y el vector ${ }^{(9-11)}$.
Dicha enfermedad tiene un comportamiento endémico y epidémico en Guayaquil. Si bien los factores que influyen en la transmisión del dengue se conocen, no se sabe cómo inciden en las tendencias de la enfermedad. El objetivo del estudio fue establecer los factores relacionados en la dinámica del dengue en la ciudad de Guayaquil, basado en tendencias históricas durante el período 2008 a 2013.

\section{METODOLOGÍA}

La investigación fue de diseño no experimental, tipo longitudinal de tendencia, siendo su población la ciudad de Guayaquil. Los casos estudiados fueron a partir del año 2008 al 2013, donde previamente se realizó una revisión de las bases de datos de casos atendidos por el sistema de salud del cantón Guayaquil. Se aplicó un instrumento de recolección de información para cada una de las variables y se procedió al análisis de observación de las series de casos de dengue, desde el punto de vista virológico y entomológico dados por el Ministerio de Salud Pública (MSP) ${ }^{(12)}$. En lo que respecta a la temperatura, humedad y vientos por semanas epidemiológicas, se tomó como base la información pública dada por el Instituto Nacional de Hidrología y Meteorología (INHAMI) (13-15).
Se utilizó un registro de la información, datos validados y almacenados mediante códigos en el programa de computación Excel 2007. Luego de ser tabulados, se los presenta en forma de figuras. El análisis estadístico del comportamiento del dengue y de los factores ambientales fue por semanas epidemiológicas, y del virológico y entomológico por períodos epidemiológicos ${ }^{(16,17)}$.

Se determinaron tendencias a los indicadores obtenidos y se aplicaron pruebas estadísticas y el uso del coeficiente de determinación $\left(R^{2}\right)$, considerándose el resultado mejor para la toma de decisiones cuando sean mayores a $60 \%$ (porcentaje de variabilidad) y más aún cercano al $100 \%{ }^{(18)}$. Para estimar la tendencia se consideró entre otras pruebas la tendencia lineal y logarítmica, en la que si existe un resultado con los parámetros adecuados comparado con los puntos de presentación de la tendencia, se considera fiable. Al utilizar el método de tendencia polinómica hay que considerar que al obtener un mayor porcentaje de variabilidad aumenta la fiabilidad; este método permite observar un pronóstico cercano a la realidad que pueda predecir la continuidad de la tendencia reflejado en el comportamiento del evento.

En la parte ética, este trabajo fue de tipo ecológico (población), por lo que no

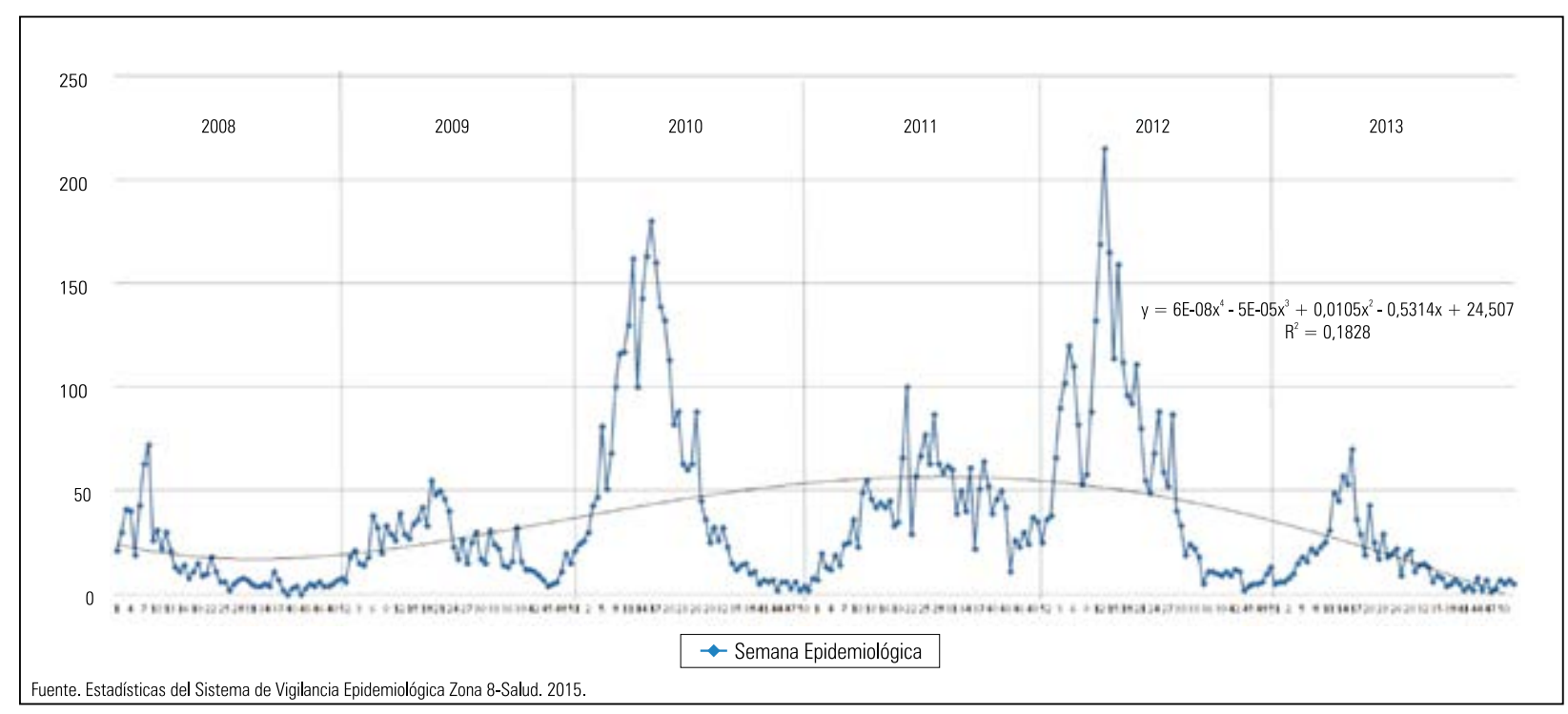

Figura 1. Tendencia del dengue en Guayaquil por semanas epidemiológicas. Período 2008 - 2013. 


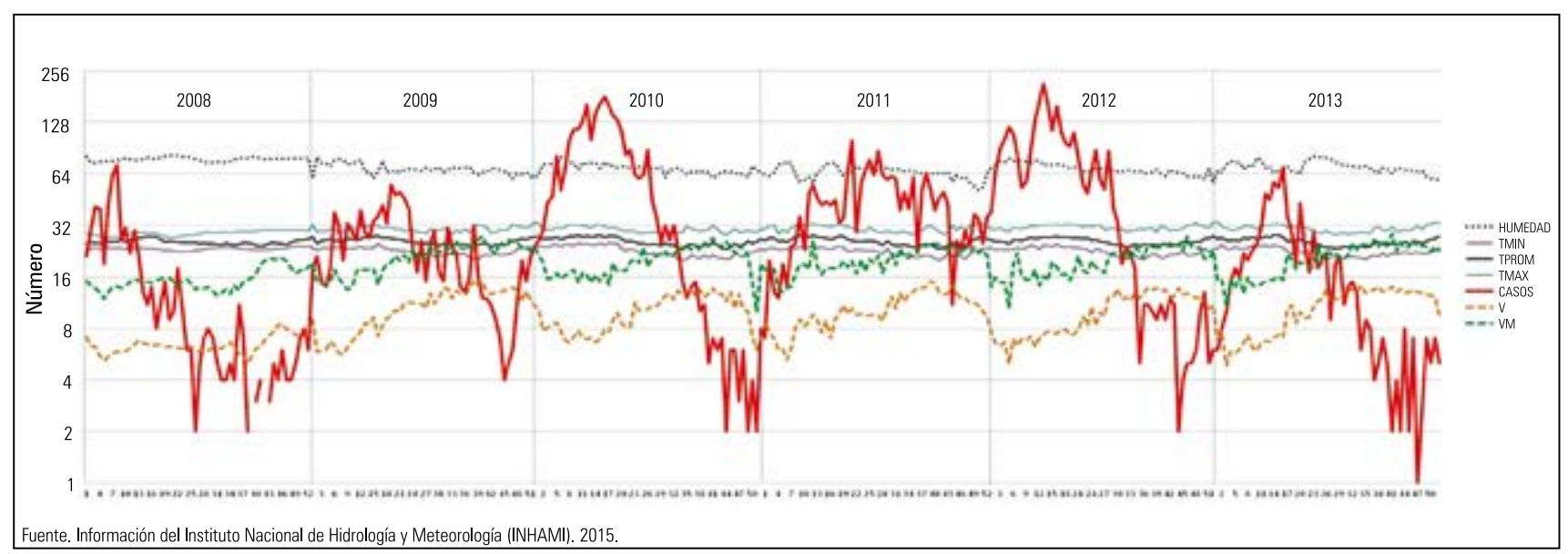

Figura 2. Comportamiento del dengue en Guayaquil comparado con factores ambientales.

se trabajó con individuos, y se solicitó la aprobación de la autoridad de salud correspondiente para la información de tipo epidemiológica.

\section{RESULTADOS}

Se realizó una línea de tendencia polinómica de orden 5 para el comportamiento del dengue en Guayaquil. Los puntos de la línea de tendencia de los años 2010 y 2012 fueron lejanos y de los años 2008, 2009 y 2013 cercanos al comportamiento. Dicha tendencia dio mejor representatividad, cuyo resultado fue de $18 \%$ de variabilidad, permitiendo observar la dispersión de puntos del comportamiento con respecto a la línea de tendencia (figura 1).

El dengue, comparado con factores ambientales de temperatura, humedad y vientos, en su conjunto muestra hallazgos que pueden influenciar en el comportamiento del dengue; así la temperatura alta con humedad promedio y escasos vientos provocarían condiciones para que exista un incremento en la intensidad de la transmisión de la enfermedad (figura 2).

Al analizar la presentación de los casos con la temperatura promedio semana a semana que está dada entre 23 a 28 grados centígrados, se tuvo el hallazgo de que cuando disminuye la temperatu- ra bajan los casos o cuando aumenta la temperatura por encima del límite superior promedio que se encuentra entre los 28 a 33 grados centígrados, los casos se incrementan, pero con un porcentaje de variabilidad no fiable (figura 3 ).

Asimismo, la variable humedad mantiene un promedio de 50 a $80 \%$, observándose un aumento de casos cuando existe una humedad por encima del $70 \%$, lo que podría dar condiciones favorables para el mantenimiento de la transmisión de la enfermedad; es decir, que a humedad promedio alta en la etapa lluviosa se relaciona con el aumento del dengue, con un porcentaje de variabilidad no fiable (figura 4).

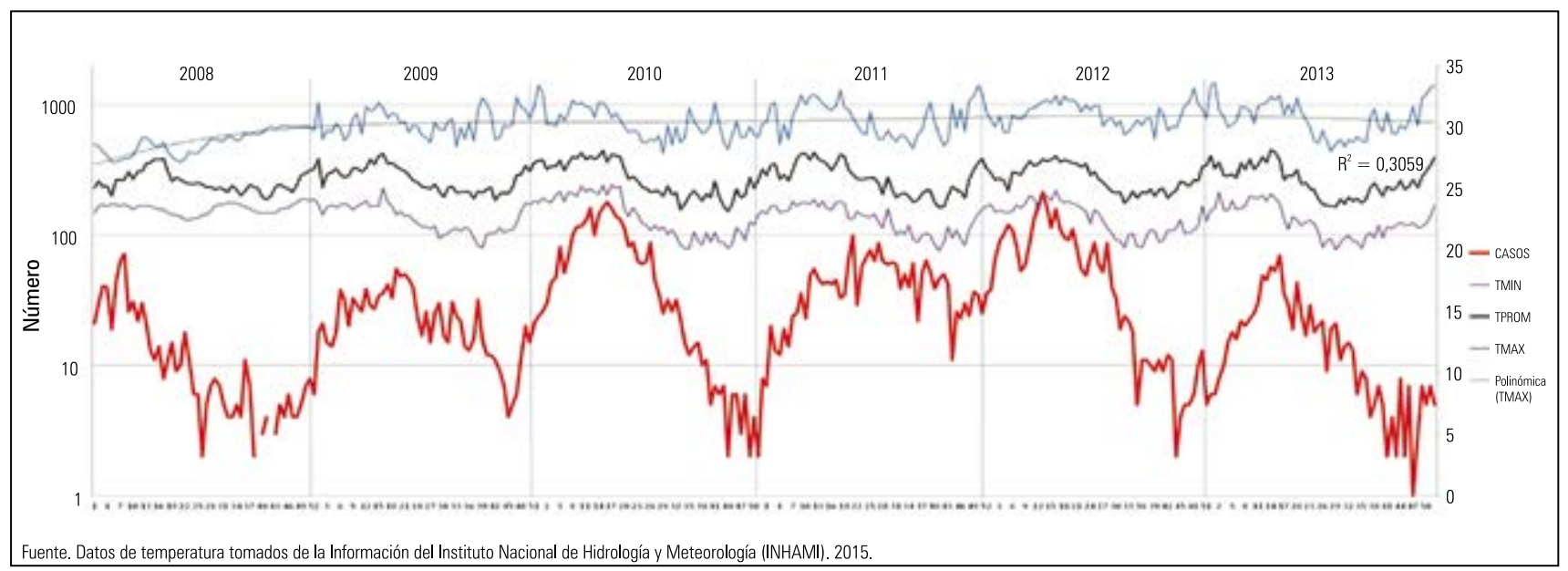

Figura 3. Comportamiento del dengue en Guayaquil por semanas epidemiológicas comparado con factor ambiental de temperatura. 


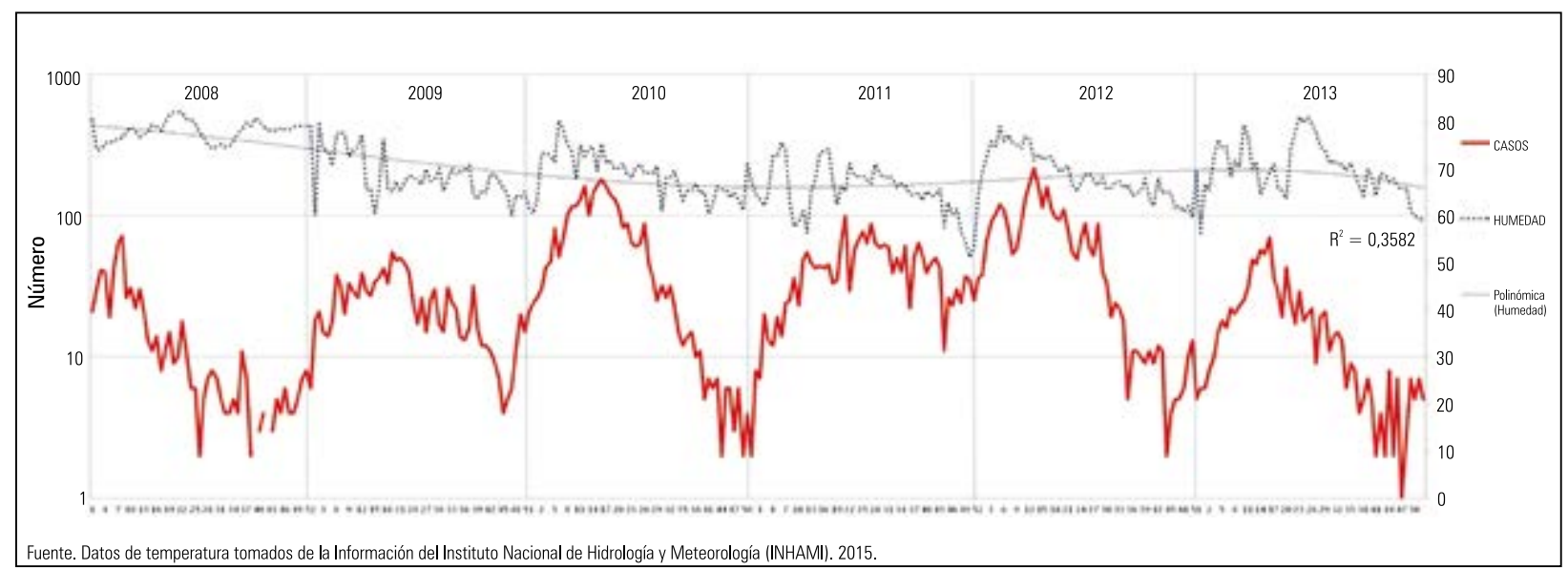

Figura 4. Comportamiento del dengue en Guayaquil por semanas epidemiológicas comparado con factor ambiental de humedad.

En cuanto a los vientos y ráfagas de vientos, se observa que cuando aumentan los vientos disminuye la presentación de casos y cuando disminuyen los vientos hay propensión al aumento de casos, pero con un porcentaje de variabilidad no fiable (figura 5).

Se utilizó el indicador entomológico del índice de Breteau para evaluar el nivel de infestación por el mosquito Aedes aegypti, debido a que establece una relación entre los recipientes positivos y las viviendas inspeccionadas, considerado el más informativo para medir el riesgo de transmisión del dengue. En este estudio, el primer período (semanas 1 a 13) se ob- servó que en todos los años ha predominado el riesgo alto, así como el segundo período (semanas 14 a 26), a excepción del 2012, que coincide con la etapa invernal; luego decrece este indicador para el tercer período (semana 27 a 39) en los años 2012 y 2013 y también en el cuarto período (semana 40 a 52) de los 2 últimos años, donde predomina el indicador de riesgo bajo; pero los años anteriores ha habido un comportamiento de indicadores altos con un porcentaje de variabilidad no representativo (figura 6).

Al observar el comportamiento del serotipo de virus circulante del dengue en la ciudad de Guayaquil durante el período
2008 a 2013, se observó en el año 2008 la presencia del virus DEN1 y DEN3 en el primer período y los restantes períodos solo la presencia del DEN1. En el 2009 se observa del virus DEN1 y DEN2 en el primer período y los restante períodos solo la presencia del DEN1; esto fue diferente en el 2008 cuando se detectó otro virus en el primer período. En 2010 solo estuvo presente el DEN1 durante todo el año. En 2011 existió la presencia de 3 serotipos circulantes simultáneamente desde el primer período, que fueron DEN1, DEN2, y DEN4, con predominio del DEN1, pero con incremento de la presencia del DEN4. La presentación en el año 2012 de

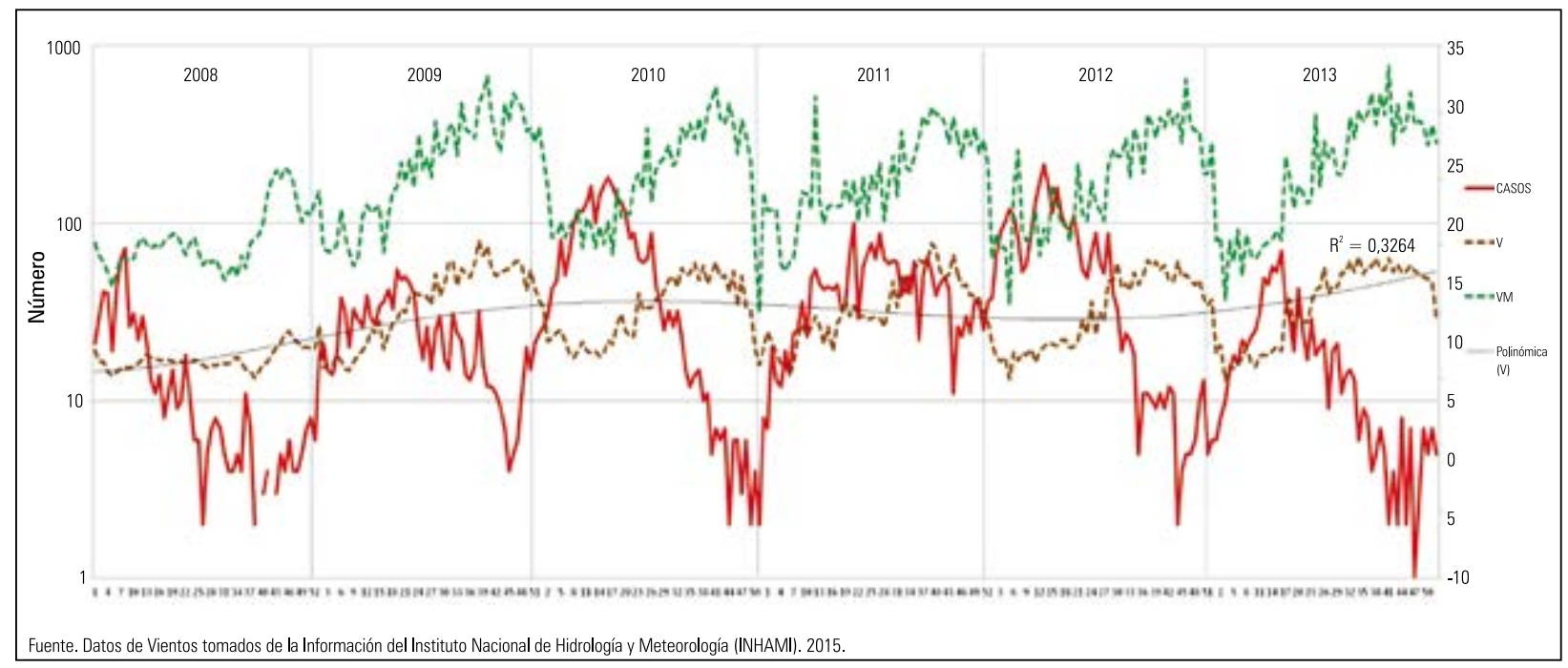

Figura 5. Comportamiento del dengue en Guayaquil por semanas epidemiológicas comparado con factor ambiental de vientos. 


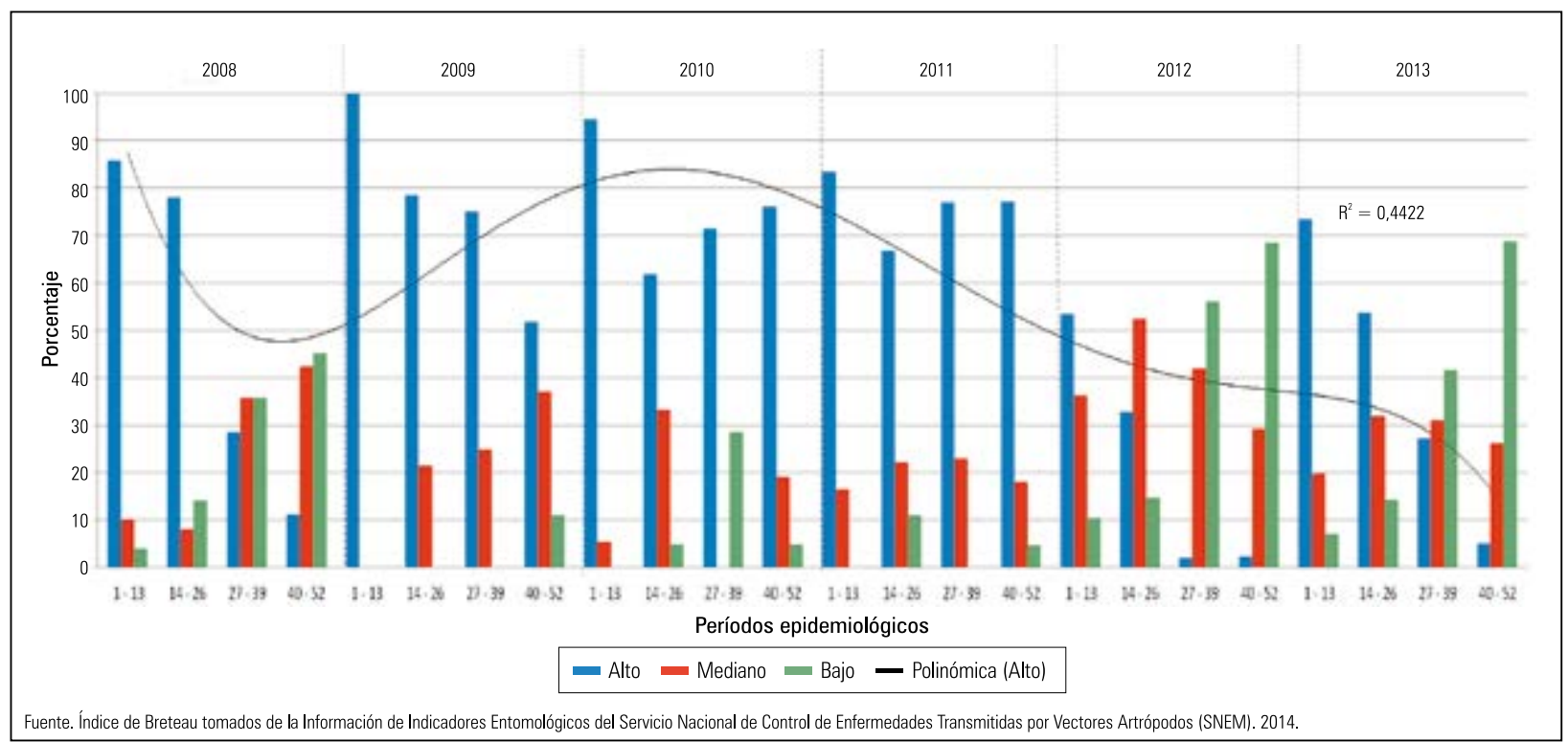

Figura 6. Índice de Breteau por período epidemiológico.

igual manera estuvo dada por el DEN1, DEN2, y DEN4, con predominio del DEN1 e incremento de la presencia del DEN4 en todo el año y permanencia del DEN2 durante los tres primeros períodos. En 2013 continuó la circulación viral de los serotipos DEN1, DEN2, y DEN4, con predominio del DEN2 (figura 7).

Para establecer la tendencia de casos de dengue proyectada al 2017, teniendo como base los años investigados, se realizaron varias pruebas, entre ellas, la tendencia lineal, obteniéndose el 31\%, y la logarítmica con 40\%; su significado no se acerca al comportamiento del evento, considerándose a estas no fiables. Observadas las tendencias lineal y logarítmica, se procedió a realizar la tendencia polinómica, donde se aplicó pruebas estadísticas y el uso del coeficiente de determinación $\left(R^{2}\right)$, dando el 63,3\% de variabilidad, con un incremento de casos en los años proyectados, siendo su resultado fiable para la toma de medidas por parte de los decidores (figura 8).

\section{DISCUSIÓN}

Se revisó la tendencia histórica de comportamiento del dengue en Guayaquil, observándose en la época invernal existe el mayor número de casos, habiendo

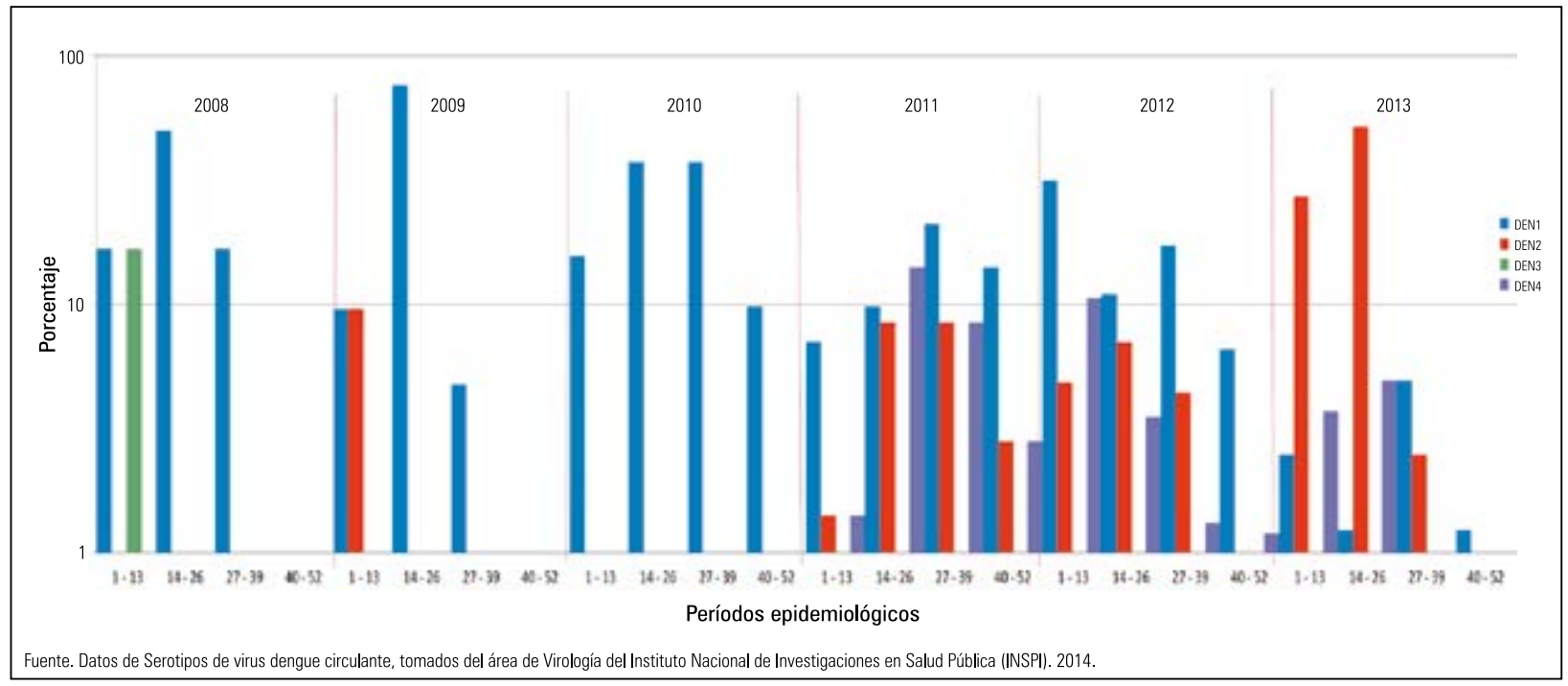

Figura 7. Serotipo de virus circulante en Guayaquil por período epidemiológico. 


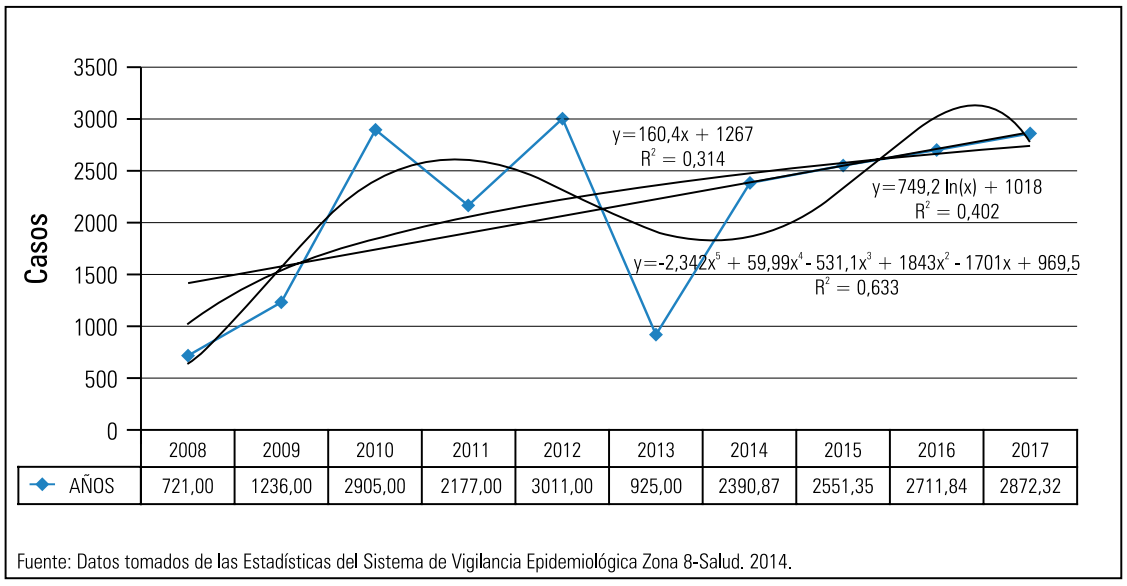

Figura 8. Tendencia del dengue en Guayaquil por años con proyección al 2017

presencia de la enfermedad durante todo el año; y los años 2010 y 2012 de mayor incidencia fueron considerados de transmisión endémico - epidémica intensa, existiendo variabilidad en su comportamiento.

Se establecieron picos epidémicos presentados en los dos primeros períodos de cada año que se relacionan en los mismos períodos con los índices de Breteau elevados, considerados de riesgo alto. Esta relación puede influir en la transmisión de la enfermedad. Aunque, es importante destacar que para los dos últimos períodos epidemiológicos su transmisión disminuye y puede estar relacionado a la moderación o baja del índice de Breteau u otro factor condicionante.

Ha existido la presencia de los 4 serotipos de dengue con circulación simultánea de 3 serotipos durante los últimos 3 años, creando una situación que pone en riesgo de dengue grave a Guayaquil en un futuro próximo, por la historicidad de lo sucedido en las décadas anteriores en Guayaquil y en los países de la región.

Existen limitaciones en cuanto a los factores ambientales como temperatura, humedad y vientos, que ante la variabilidad presentada sus valores de tendencia no son fiables para establecer su relación directa frente al comportamiento, pero contribuyen a la orientación en la transmisión de la enfermedad.

En conclusión, vista la tendencia polinómica proyectada al 2017, el 63,3\% se- ñala un incremento de casos de dengue en los años proyectados, si es que no se actúa al respecto. La presencia del virus dengue circulante en Guayaquil puede haber influido en la forma del comportamiento de la enfermedad presentándose en los últimos años una tendencia al incremento de casos. Sería relevante incluir otros factores ambientales y en un contexto completo realizar modelos de pronóstico cercano a la realidad que pueda predecir la tendencia reflejada en el comportamiento de Dengue en Guayaquil.

Se recomienda continuar los estudios de comportamientos históricos del dengue con enfoque integral, ya que son importantes para orientar a tener una mejor caracterización del evento y poder situar las decisiones estratégicas para su prevención y control.

\section{REFERENCIAS BIBLIOGRÁFICAS}

1. Fuentes-Vallejo M, Higuera-Mendieta D, GarcíaBetancourt T, Alcalá-Espinosa L, Garcia-Sánchez D, Munévar-Cagigas D, Quintero J. Análisis territorial de la distribución de Aedes aegypti en dos ciudades de Colombia: aproximación desde la coremática y el enfoque ecosistémico. Cad Saúde Pública. 2015;31(3):1-14.

2. García O. Aedes aegypti, virus dengue, chinkugunia, zika y el cambio climático. Máxima alerta médica y oficial. REDVET. Revista Electrónica de Veterinaria. 2014;15(10): 1-10.

3. Fernández-Salas I, Flores-Leal A. El papel del vector Aedes aegypti en la epidemiología del dengue en México. Salud Pública Méx.1995;37Suppl:S45-52. Recuperado a partir de http://saludpublica.mx/ insp/index.php/spm/article/view/4563.
4. Vilcarromero S, Casanova W, Ampuero J, RamalAsayag C, Siles C, Diaz G, Rodríguez-Ferrucci $\mathrm{H}$. Lecciones aprendidas en el control de Aedes aegypti para afrontar el dengue y la emergencia de chikungunya en lquitos, Perú. Rev Peru Med Exp Salud Publica. 2015;32(1):172-8.

5. Bhatt S, Gething P, Brady O, Messina J, Farlow A, Moyes C, Hay S. The global distribution and burden of dengue. Nature. 2013; 496(7446):504-7.

6. Gubler D, Ooi E, Vasudevan S, Farrar J. Dengue and dengue hemorrhagic fever, 2nd Ed. Washington D.C., USA: CABI. 2014.

7. Epidemiology of dengue: past, present and future prospects. (s. f.). Recuperado 13 de marzo de 2016, a partir de http://www.ncbi.nlm.nih.gov/pmc/ articles/PMC3753061/.

8. Simmons C, Farrar J, van Vinh Chau N, Wills B. Dengue. New Eng J Med. 2012;366(15):1423-32. http://doi.org/10.1056/NEJMra1110265.

9. PLOS Neglected Tropical Diseases: Refining the Global Spatial Limits of Dengue Virus Transmission by Evidence-Based Consensus. (s. f.). Recuperado 13 de marzo de 2016, a partir de http://journals. plos.org/plosntds/article?id=10.1371/journal. pntd.0001760.

10. Hernández M, Arboleda D, Arce S, Benavides A, Tejada P, Ramírez V, Cubides Á. Metodologia para elaborar canales endémicos. Tendencia de la notificación de Dengue, Valle del Cauca-Colombia, años 2009-2013. Biomédica. 2015;36(0). http://doi. org/10.7705/biomedica.v36i0.2934.

11. Medina A. Evolución y tendencias de la salud pública. Colombia 1993-2013. Rev Med. 2015;37(3):266-75.

12. Bisset J. Una propuesta de estrategia integral para la prevención y el control sostenible del Dengue dengue y del Aedes aegypti en Cuba. Panorama Cuba y Salud. 2014;1(2):10-3.

13. Chávez L, Moreano R. Sistema de información para la interpolación de datos de temperatura y precipitación del Ecuador. Rev Politécnica. 2013;32(0). Recuperado a partir de http://www. revistapolitecnica.epn.edu.ec/ojs2/index.php/ revista_politecnica2/article/view/52

14. Hernández O, Montaño T, Quentin E, Maldonado J, Solano J. Homogeneización de series de velocidad del viento mensuales en las estaciones meteorológicas del INAMHI en Loja, Ecuador. Rev Climatología. 2013;13. Recuperado a partir de http://webs.ono.com/reclim2/reclim13d.pdf

15. Stewart-Ibarra A, Lowe R. Climate and non-climate drivers of dengue epidemics in southern coastal Ecuador. Am J Trop Med Hyg. 2013;88(5):971-81.

16. Montesano-Castellanos R. Vigilancia epidemiológica del dengue en México. Salud Pública de México. 2015;37(0). Recuperado a partir de http://saludpublica.mx/insp/index.php/spm/article/ view/4565

17. Quintana C. Seroprevalencia y factores de riesgo de dengue en pacientes atendidos en los centros de salud del cantón Durán, periodo 2009-2011. Propuesta de medidas de prevención. 2013. Recuperado a partir de http://repositorio.ug.edu. ec/handle/redug/7595.

18. Rúa-Uribe G, Suárez-Acosta C, Chauca J, Ventosilla P, Almanza R. Modelling the effect of local climatic variability on dengue transmission in Medellin (Colombia) by means temporary series analysis. Biomedica. 2013;33:142-52. 